\title{
TU/e EmonOWEN

\section{A combined NMR and XRD study of AFI and AEL type molecular sieves}

\section{Citation for published version (APA):}

Peeters, M. P. J., Ven, van de, L. J. M., Haan, de, J. W., \& Hooff, van, J. H. C. (1993). A combined NMR and XRD study of AFI and AEL type molecular sieves. Journal of Physical Chemistry, 97(31), 8254-8260. https://doi.org/10.1021/j100133a023

DOI:

10.1021/j100133a023

Document status and date:

Published: 01/01/1993

\section{Document Version:}

Publisher's PDF, also known as Version of Record (includes final page, issue and volume numbers)

\section{Please check the document version of this publication:}

- A submitted manuscript is the version of the article upon submission and before peer-review. There can be important differences between the submitted version and the official published version of record. People interested in the research are advised to contact the author for the final version of the publication, or visit the $\mathrm{DOI}$ to the publisher's website.

- The final author version and the galley proof are versions of the publication after peer review.

- The final published version features the final layout of the paper including the volume, issue and page numbers.

Link to publication

\section{General rights}

Copyright and moral rights for the publications made accessible in the public portal are retained by the authors and/or other copyright owners and it is a condition of accessing publications that users recognise and abide by the legal requirements associated with these rights.

- Users may download and print one copy of any publication from the public portal for the purpose of private study or research.

- You may not further distribute the material or use it for any profit-making activity or commercial gain

- You may freely distribute the URL identifying the publication in the public portal.

If the publication is distributed under the terms of Article 25fa of the Dutch Copyright Act, indicated by the "Taverne" license above, please follow below link for the End User Agreement:

www.tue.nl/taverne

Take down policy

If you believe that this document breaches copyright please contact us at:

openaccess@tue.nl

providing details and we will investigate your claim. 


\title{
A Combined NMR and XRD Study of AFI and AEL Type Molecular Sieves
}

\author{
Mart P. J. Peeters, ${ }^{*}$ Leo J. M. van de Ven, Jan W. de Haan, and Jan H. C. van Hooff \\ Eindhoven University of Technology, Schuit Institute of Catalysis, PO Box 513, \\ $5600 \mathrm{MB}$ Eindhoven, The Netherlands
}

Received: March 3, 1993; In Final Form: May 7, 1993

\begin{abstract}
Calcined dehydrated $\mathrm{AlPO}_{4}-5$ has been studied by X-ray powder diffraction, ${ }^{31} \mathrm{P}$ MAS, and ${ }^{27} \mathrm{Al}$ MAS and double-rotation (DOR) NMR. The results indicate that three crystallographically different sites can be distinguished in the structure of dehydrated $\mathrm{AlPO}_{4}-5$ in the ratio 1:1:1. The observed splitting of the NMR spectra is correlated to the line width of the XRD peaks between $2 \theta=19^{\circ}$ and $2 \theta=23^{\circ}$. Simulations of ${ }^{27} \mathrm{Al}$ DOR $(4.7,9.4$, and $11.7 \mathrm{~T})$ and MAS spectra $(7.0$ and $9.4 \mathrm{~T})$ yield the isotropic chemical shifts $\left(\delta_{\text {iso }}\right)$, quadrupolar coupling constants $\left(C_{\mathrm{Q}}\right)$, and the asymmetry parameters $(\eta)$ of the different sites in dry AFI. The interaction of water, methanol, ammonia, and acetonitrile with $\mathrm{AlPO}_{4}-5$ and $\mathrm{AlPO}_{4}-11$ is studied by XRD and ${ }^{27} \mathrm{Al}$ DOR and MAS NMR. Both water and ammonia are able to coordinate to part of the framework aluminum, leading to five- and/or six-coordinated aluminum. The relative amounts of five- and six-coordinated aluminum depend on the crystal structure and the interacting sorbate. Whereas water in $\mathrm{AlPO}_{4}-11$ is interacting with one specific aluminum site $\left(\mathrm{Al}_{2}\right)$, the interaction of water with $\mathrm{AlPO}_{4}-5$ occurs randomly. This leads to a broadening of the tetrahedral signals at higher water loading (above 10-12 wt \%). At low MAS frequencies some dipolar broadening occurs, whereas at high spinning frequencies or $850-1000 \mathrm{~Hz}$ DOR the broadening is caused by site distribution. Methanol and acetonitrile do not interact with framework atoms. These molecules are too big to coordinate to framework aluminum in AFI and AEL type molecular sieves. The broadening of the spectral features observed after methanol adsorption is apparently due to an increase in chemical shift dispersion brought about by nonspecific interactions of methanol with the framework, thereby causing a larger spread in Al-O-P angles.
\end{abstract}

\section{Introduction}

$\mathrm{AlPO}_{4}-5$ (AFI) and $\mathrm{AlPO}_{4}-11$ (AEL) are two of a series of molecular sieves first synthesized by the Union Carbide Corporation. The structures are built of alternating $\mathrm{AlO}_{4}^{-}$and $\mathrm{PO}_{4}^{+}$ tetrahedra, which are connected via bridging oxygen atoms to form a one-directional pore system with a diameter of $7.3 \AA$ (12-membered rings) in the case of AFI and $3.9 \times 6.4 \AA(10-$ membered rings) in the case of AEL. On the basis of neutron diffraction, ${ }^{1}$ it was concluded that the dehydrated AFI structure contains a unique $\mathrm{T}$-site for both $\mathrm{Al}$ and $\mathrm{P}$, while three crystallographically different sites can be distinguished in the dry AEL molecular sieve. Upon hydration of AEL a change of symmetry is observed, leading to five T-sites. The structure of AEL in relation with NMR and XRD was reported in a previous publication. ${ }^{2}$

Recently, the results of a ${ }^{27} \mathrm{Al}$ DOR NMR study of hydrated and dehydrated VPI-5 (VFI) and AFI were reported. ${ }^{3}$ For calcined (dehydrated) VFI two different peaks in the ratio 2:1 can be observed for the three different crystallographic sites, at least for some magnetic field strengths. Upon hydration of the sample, the line widths of the tetrahedral aluminum resonances do not increase and a signal at $-15.5 \mathrm{ppm}$ is formed, with a line width comparable to the signals of aluminum in the tetrahedral region. Separate resonances for all three crystallographic sites can be observed. The ${ }^{27} \mathrm{Al}$ DOR NMR spectrum of calcined dehydrated AFI at $11.7 \mathrm{~T}$ consists of a single line at $36.1 \mathrm{ppm}$, which is consistent with the neutron diffraction study. However, the line width (at half-height) of the ${ }^{27} \mathrm{Al}$ DOR NMR signal of tetrahedrally coordinated aluminum in dehydrated AFI is more than twice as large as the line width of the (single) lines of dehydrated VFI, indicating that the observed signal might well be an envelope of signals. Upon water adsorption, the line width of the tetrahedral NMR signal (39.3 ppm) increases significantly, and the resonances of both five- and six-coordinated aluminum are observed at +5 and $-14 \mathrm{ppm}$, respectively. The broadening of the signal is ascribed to either the formation of hydroxide defects or nonselective adsorption of water molecules in the relatively narrow channels of AFI. This would produce a large distribution of ${ }^{27} \mathrm{Al}$ environments leading to a spread of the NMR resonances over a large spectral range.

In contrast to the situation in zeolites, small polar molecules are able to coordinate to part of the framework aluminum atoms in aluminophosphates. The adsorption of small polar molecules in aluminophosphates has been the subject of many studies. ${ }^{46}$ Water is known to transform part of the aluminum of AFI type molecular sieves into five- and six-coordinated aluminum, while only four- and six-coordinated aluminum is found in the AEL type molecular sieves. Adsorption of ammonia leads to five- and six-coordination of part of the aluminum in AFI type molecular sieves, while methanol does not. ${ }^{4}$ Two possible explanations were given for the fact that methanol adsorption did not lead to a strong coordination to part of the aluminum: methanol is not as good a ligand as water, and ammonia or methanol is too large to coordinate to the aluminum.

Here, we report the results of a ${ }^{27} \mathrm{Al}$ DOR NMR study of a series of AFI molecular sieves obtained via three independent syntheses. The products are further characterized by ${ }^{31} \mathrm{P}$ MAS NMR, XRD, and $n$-butane adsorption. The results indicate that three crystallographically different $T$-sites can be distinguished in the dry AFI molecular sieve.

The adsorption of small polar molecules on AFI and AEL type molecules was studied with XRD and ${ }^{27} \mathrm{Al}$ DOR and MAS NMR. Water and ammonia transform part of the tetrahedrally coordinated aluminum into five- and/or six-coordinated aluminum. Adsorption of water and ammonia in AFI causes broadening of the spectral features in ${ }^{27} \mathrm{Al} \mathrm{NMR}$, eventually leading to a single broad signal for the tetrahedrally coordinated aluminum. Methanol and acetonitrile are too bulky to coordinate to the aluminum in AFI and AEL type molecular sieves.

\section{Experimental Section}

Syntheses. AFI, AEL, and $\mathrm{COAPO}_{4}-5$ samples were prepared by a method described in the patent literature. ${ }^{7,8} \mathrm{~A}$ gel with a molar composition of $1.02 \mathrm{P}_{2} \mathrm{O}_{5}: \mathrm{Al}_{2} \mathrm{O}_{3}: y$ template: $\approx 40-50 \mathrm{H}_{2} \mathrm{O}$ 
was prepared. Some $\mathrm{Co}(\mathrm{OAc})_{2}((\mathrm{Al}+\mathrm{P}) / \mathrm{Co}=4000)$ was added to the diluted phosphoric acid for the synthesis of CoAPO-5 molecular sieves. For the syntheses of AFI samples both tripropylamine (samples 1 and 2) and triethylamine (sample 3) were used as template $(y=1.5)$, while for the $\mathrm{CoAPO}_{4}-5$ samples triethylamine $(y=1.5)$ was used. The template used for the crystallization of AEL was di- $n$-propylamine $(y=1.0)$. Crystallization was performed by heating the gels in stainless steel Teflon-lined autoclaves at $423 \mathrm{~K}$ for 1-2 days. After quenching of the autoclaves, the crystalline product was separated from the mother liquor by sedimentation or centrifugation. After drying of the samples, calcination was performed by heating the samples in a flow of dry oxygen at a rate of $1 \mathrm{~K} \mathrm{~min}^{-1}$ to $873 \mathrm{~K}$ and keeping them at the final temperature for $5 \mathrm{~h}$.

Characterization. X-ray diffraction measurements were performed on a Philips PW 7200 diffractometer at room temperature. Spectra were recorded between $2 \theta=5^{\circ}$ and $2 \theta=50^{\circ}$ with a scanning rate of $1 \mathrm{deg} \mathrm{min}^{-1}$.

Pore volumes were determined gravimetrically using $n$-butane adsorption on a Cahn 2000 electrobalance. This electrobalance was also used to check the loading of sorbates on the aluminophosphates before and after the ${ }^{27} \mathrm{Al}$ DOR NMR measurements. No significant changes in the loading of the samples were observed before and after the DOR NMR measurements.

${ }^{27} \mathrm{Al}$ DOR NMR spectra at different magnetic fields were measured on Bruker MSL spectrometers. The pulse length was varied between 1 and $3 \mu \mathrm{s}$, corresponding to a flip angle of approximately $20^{\circ}$. A recycle delay of $1 \mathrm{~s}$ was used. The outer rotor was spun at $850-1000 \mathrm{~Hz}$ with the inner rotor spinning at $4-5 \mathrm{kHz}$. Typically $800-1000$ pulses were accumulated. Rotor synchronized pulsing was applied to suppress the odd numbered spinning sidebands. ${ }^{9}$ Rotation of the inner rotor cannot be monitored directly with the present equipment. However, a sudden stop of the inner rotor during the measurement invariably results in a frequency drop of $20-30 \mathrm{~Hz}$ of the outer rotor. Additionally, rotation of the inner rotor was checked when slowing down the outer rotor; after a crash, a restart was always quite easily audible.

${ }^{31 P}$ and ${ }^{27} \mathrm{Al}$ MAS NMR measurements were recorded on a Bruker MSL 400 spectrometer using a 4-mm double bearing MAS probe. A recycle delay of $60 \mathrm{~s}$ was found sufficiently long to record ${ }^{31} P$ MAS NMR spectra that were unaffected by further enlarging of the delay. A spinning rate of $10.0 \mathrm{kHz}$ was used. ${ }^{27} \mathrm{Al}$ MAS NMR spectra were recorded using a pulse length of $1 \mu \mathrm{s}$, corresponding to a flip angle of approximately $20^{\circ}$. A recycle delay of $1 \mathrm{~s}$ was used. High-power proton decoupling was applied when appropriate.

\section{Results and Discussion}

The X-ray diffraction patterns of some calcined dehydrated AFI molecular sieves are given in Figure 1. It can be seen that all samples are highly crystalline and that only one sample (AFI2 ) is contaminated with a small amount of some dense phase material, probably trydimite. The ${ }^{27}$ Al DOR NMR and ${ }^{31}$ PMAS NMR spectra, however, show some interesting differences (Figure 2). Two of the three synthesis procedures, AFI synthesized with tripropylamine (AFI-1 and AFI-2) and $\mathrm{COAPO}_{4}-5$ synthesized with triethylamine (not shown), yield samples of which both the ${ }^{27} \mathrm{Al}$ DOR NMR and ${ }^{31}$ P MAS NMR spectra show (at least) two signals. The total widths of these signals are not significantly larger than the widths of the single signal for the other samples. To the best of our knowledge there are, however, no indications in the literature which might indicate the existence of more than one crystallographically different site in this aluminophosphate structure.

There is, however, one paper where two signals in the ${ }^{31}$ P MAS NMR spectra are observed if the $\mathrm{Al} / \mathrm{P}$ ratio of the sample is much higher than unity. ${ }^{10}$ In that case the ${ }^{31} \mathrm{P}$ MAS NMR spectrum shows two signals at -28.5 and $-17.2 \mathrm{ppm}$, while the

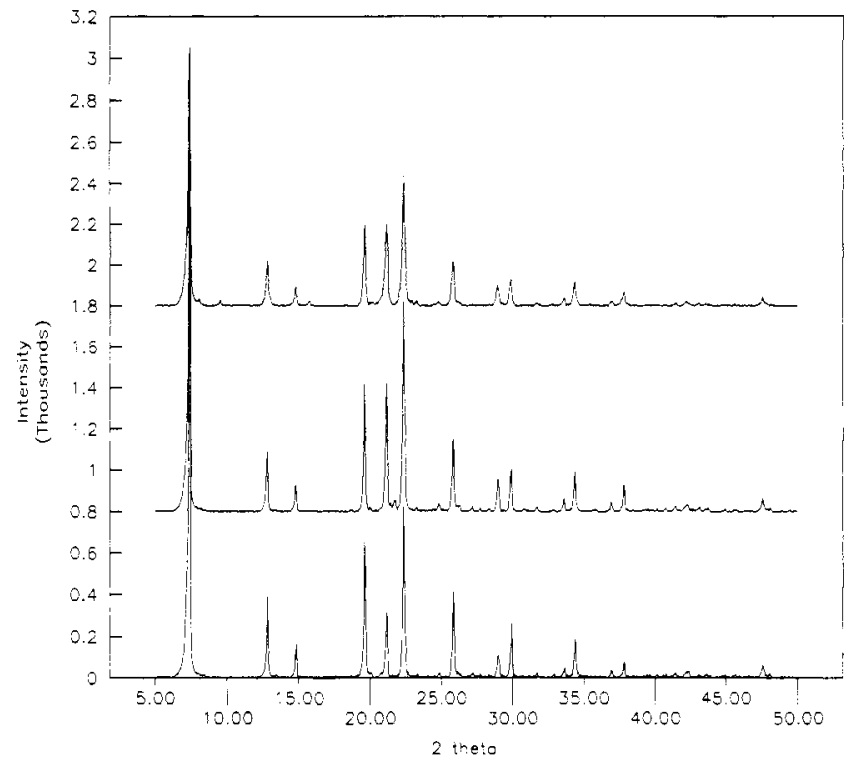

Figure 1. XRD patterns of some of the AFI samples: AFI-1 (bottom), AFI-2 (middle), and AFI-3 (top).

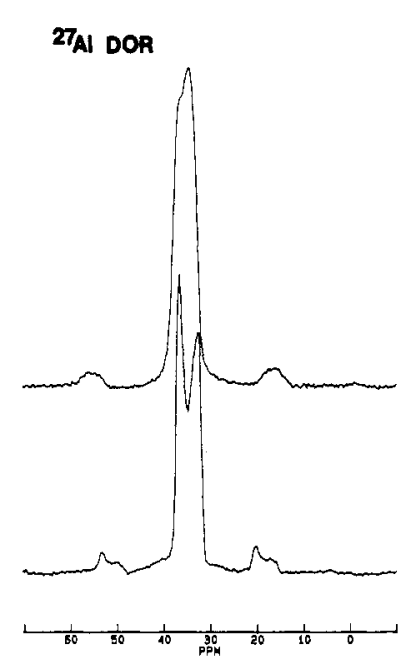

31P MAS

Figure 2. ${ }^{27} \mathrm{Al}$ DOR (left) and ${ }^{31} \mathrm{P}$ MAS NMR (right) spectra of dry AFI-1 (bottom) and AFI-3 (top) measured at 9.4 T. The signal at -20 ppm in the ${ }^{31}$ P MAS NMR spectrum of AFI-1 is caused by an impurity.

${ }^{27} \mathrm{Al}$ MAS NMR spectrum of the sample is identical to a sample with an $\mathrm{Al} / \mathrm{P}$ ratio of 0.98 . The reported splitting of the peaks in the ${ }^{31}$ P MAS NMR spectra (two signals at approximately -24 and $-28 \mathrm{ppm}$ ) is, however, too big to explain our observations. Furthermore, our samples have an $\mathrm{Al} / \mathrm{P}$ ratio close to one.

It seems unlikely that the pore volume is related with the local ordering around phosphorus and aluminum which is measured with NMR. ${ }^{27} \mathrm{Al}$ DOR and ${ }^{31} \mathrm{P}$ MAS NMR measurements on samples with small $(0.05-0.08 \mathrm{~mL} / \mathrm{g})$ and large pore volumes $(0.11 \mathrm{~mL} / \mathrm{g})$ indicated no correlation between the results obtained with these two techniques. The small pore volume observed for some samples remains a matter of further investigation. It might be explained by blockage of the pores with some extraframework aluminum and/or phosphorus which, because of the small amount, is invisible for NMR or to stacking faults, earlier reported for $\mathrm{AlPO}_{4}-8$ (AET) molecular sieves. ${ }^{3}$

A closer examination of the XRD spectra yielded a further distinction between the samples obtained via the different syntheses. A more detailed study of the reflections between $2 \theta$ $=19^{\circ}$ and $2 \theta=23^{\circ}$ reveals significant differences in intensities and, more important, line widths. For two samples with a pronounced splitting of the ${ }^{27}$ Al DOR NMR lines, AFI-1 and AFI-2, the sum of the line widths (at half-heights) amounts to $0.53^{\circ} 2 \theta$ while for the sample where no splitting is observed the 


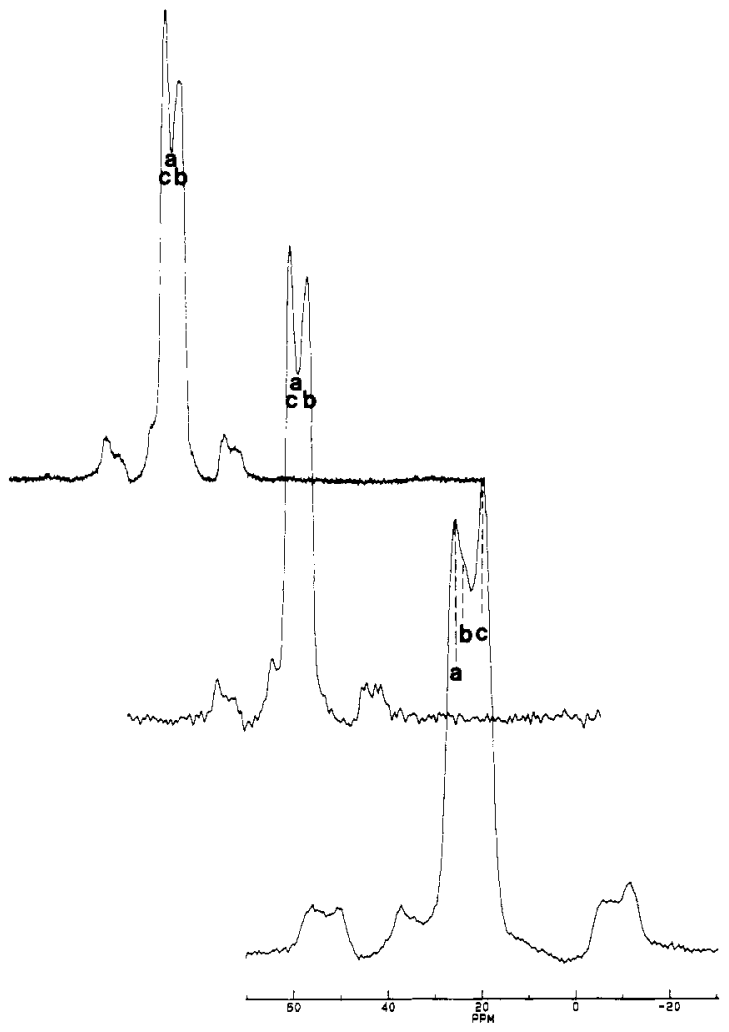

Figure 3. ${ }^{27} \mathrm{Al}$ DOR NMR spectra of dry AFI-2 measured at different magnetic field strengths: $B_{0}=4.7 \mathrm{~T}$ (bottom), $9.4 \mathrm{~T}$ (middle), and 11.7 $\mathrm{T}$ (top).

line width is equal to $0.73^{\circ} 2 \theta$. An increased line width suggests a less ordered structure (more lattice defects) or very small crystallites. Since the size of the crystals is on the order of some microns (SEM), the last explanation does not apply here. The less ordered structure may possibly lead to less ordered local environments which can then conceal the existence of more than one crystallographically different T-site in NMR. The differences in intensities of the reflections are explained by the different morphologies of the crystals which causes some reflections to be more intense.

The possibility of an intergrowth to explain the splitting in the NMR spectra is very remote in view of the relative intensities of the ${ }^{27} \mathrm{Al}$ DOR NMR signals. Simulations (see below) indicate that the relative contribution of the different lines are $33 \%$ each.

From the ${ }^{27} \mathrm{Al}$ DOR and ${ }^{31} \mathrm{P}$ MAS NMR spectra we conclude that not all $\mathrm{T}$-sites are equivalent but that there exist three different T-sites in dehydrated AFI molecular sieves. More details presumably have to await the complete Rietveld refinement of the XRD data. To the best of our knowledge, this is not available at this time. At the moment we are therefore not able to propose a new (presumably slightly altered) structure, based on XRD data.

${ }^{27}$ Al DOR NMR measurements on dry AFI-2 were performed at different magnetic fields to determine both the isotropic chemical shifts $\left(\delta_{\text {iso }}\right)$ and the quadrupolar parameters $\left(C_{\mathrm{Q}}\right.$ and $\eta$ ) of the different aluminum sites. The spectra are displayed in Figure 3; the low-field shoulder is caused by the presence of some dense phase material. At first sight, no significant increase of the resolution is obtained by measuring at magnetic field strengths of 4.7, 9.4, and 11.7 T. There is, however, a distinct change in the envelope pattern, due to overlap of the (three) separate lines; see Figure 3. Deconvolution of the DOR NMR spectra was performed using three signals with equal intensities. A plot of the DOR NMR line positions versus $100 /\left(B_{0}\right)^{2}$ is given in Figure 4. Three straight lines are observed as expected from theory. ${ }^{11}$ The slope of the line is related to the product of the quadrupolar coupling constant $C_{\mathrm{Q}}$ and $\eta$ (see formula in Figure 4). Extra-

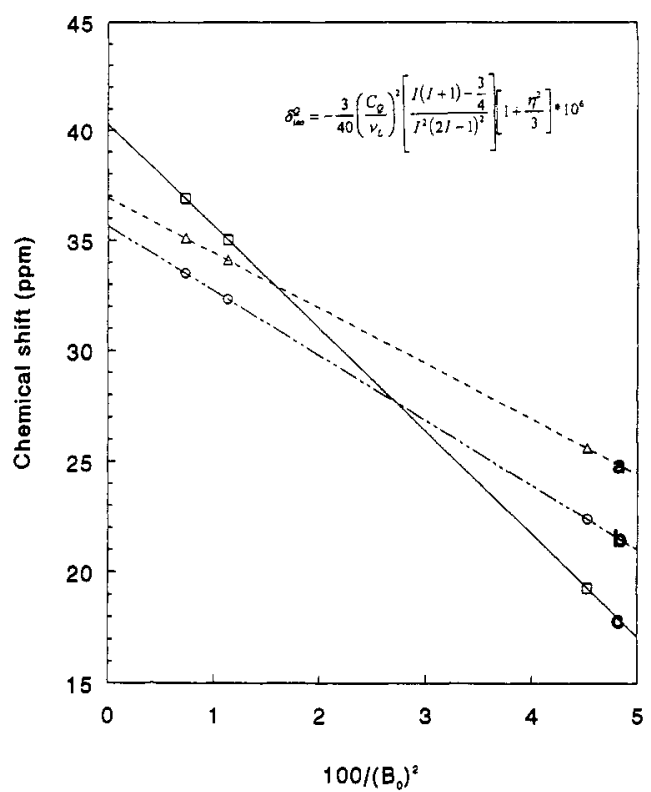

Figure 4. ${ }^{27} \mathrm{Al}$ DOR NMR line position of AFI-2 as a function of $100 /$ $\left(B_{0}\right)^{2}$.

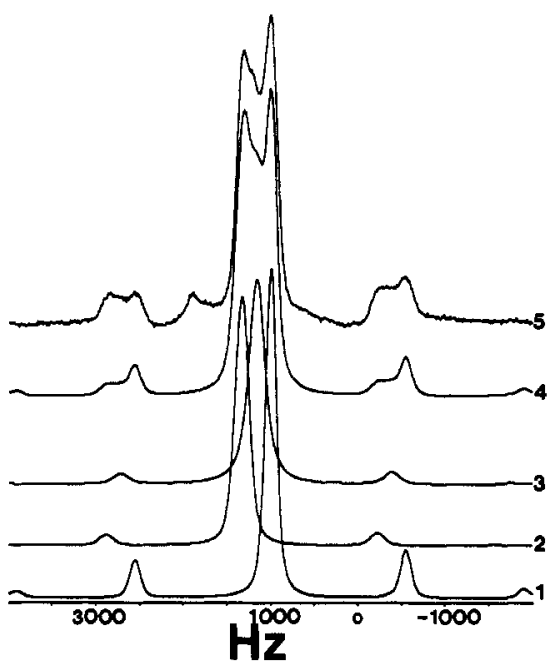

Figure 5. Individual lines (traces 1-3), simulated (trace 4), and measured (trace 5) ${ }^{27} \mathrm{Al}$ DOR spectra (4.7 T) of AFI-2.

TABLE I: Quadrupolar Parameters Used for the Simulation of Dry AFI-2

\begin{tabular}{cccc}
\hline $\begin{array}{c}\text { isotropic chemical } \\
\text { shift }(\mathrm{ppm})( \pm 0.15)\end{array}$ & $\begin{array}{c}\text { relative } \\
\text { area }(\%)( \pm 4)\end{array}$ & $\begin{array}{c}e^{2} q Q / h \\
(\mathrm{MHz})( \pm 0.1)\end{array}$ & $\begin{array}{c}\eta \\
( \pm 0.15)\end{array}$ \\
\hline 40.3 & 33 & 3.1 & 0 \\
36.9 & 33 & 2.1 & 0.65 \\
35.6 & 33 & 2.4 & 0.2
\end{tabular}

polation of the lines to infinite magnetic fields yields the isotropic chemical shift. Spectral simulations were performed with three different tetrahedral sites with equal intensities. Figure 5 displays the results of the simulation of the DOR spectrum measured at 4.7 T. The quadrupolar parameters, derived from simulation of DOR and MAS NMR spectra at various magnetic fields, of the three different peaks observed in the calcined (dry) AFI-2 sample are given in Table I.

All spectra could be simulated using a relative intensity of $33 \%$ for each aluminum site. This suggest that the 12 -membered ring of AFI, which contains six aluminum atoms, has three crystallographically different sites. The fact that the quadrupolar coupling constants of two sites are practically the same is a strong indication that we are dealing with two T-sites with only slightly different environments. The third line has a much larger quadrupolar coupling constant and isotropic chemical shift, 


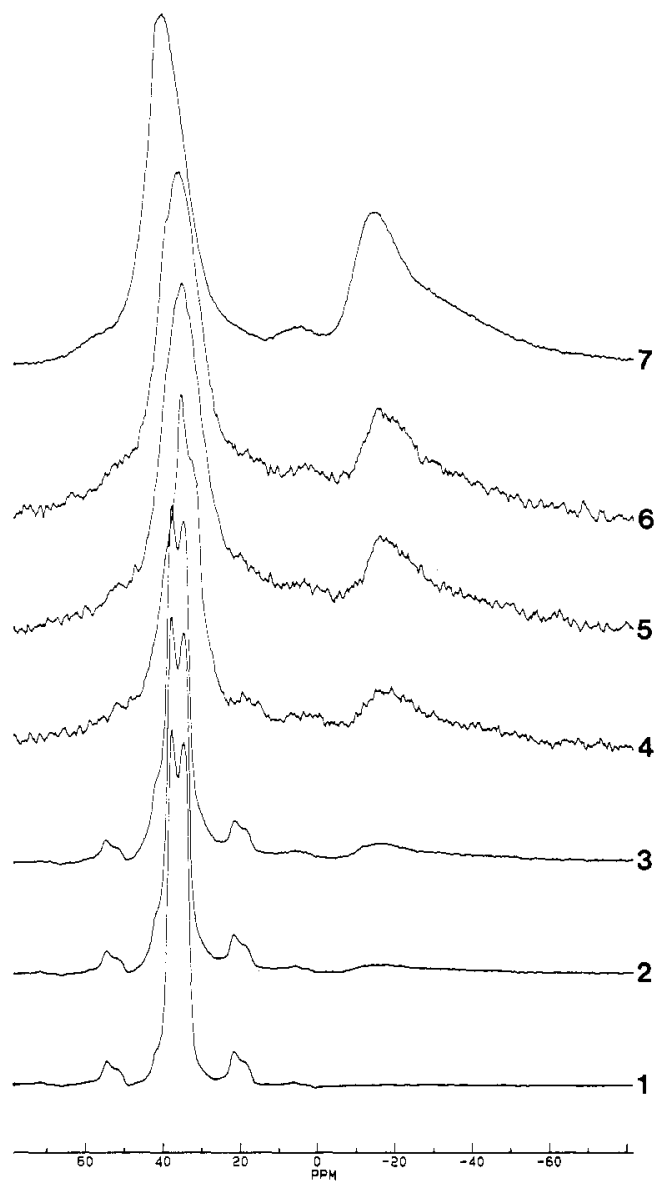

Figure 6. ${ }^{27} \mathrm{Al}$ DOR NMR spectra of AFI-2 as a function of the water content $(9.4 \mathrm{~T}$ ): dry (bottom) $3.0 \mathrm{wt} \%$ (trace 2$), 11.2 \mathrm{wt} \%$ (trace 3 ), $14.0 \mathrm{wt} \%$ (trace 4 ), $16.1 \mathrm{wt} \%$ (trace 5), $19.0 \mathrm{wt} \%$ (trace 6), and 23.8 wt \% (top).

indicating that the symmetry of this T-site is deviating more from tetrahedral symmetry than the other two sites. 2,12

Water Adsorption. The adsorption of water (dipole moment $1.85 \mathrm{D})$ in AEL has been dealt with in detail in previous publications. ${ }^{2,5}$ Here we will use some of the results reported in those publications to compare with the results we obtained for AFI.

As seen in the previous section, the ${ }^{27} \mathrm{Al}$ DOR NMR spectrum of calcined dry AFI is, depending on the synthesis conditions, either a rather broad band or a triplet. For the partial hydration of AFI, a sample with an intermediate splitting (AFI-2) was used. The spectra are displayed in Figure 6. Upon hydration, octahedrally coordinated aluminum is formed together with some pentacoordinated aluminum; this can be observed more clearly in the MAS spectra (Figure 7). The splitting in the tetrahedral region is observed up to $11-12$ wt $\%\left(\mathrm{Al} / \mathrm{H}_{2} \mathrm{O}=0.75\right)$ water adsorption. Adsorption of $14.0 \mathrm{wt} \%$ water $\left(\mathrm{Al} / \mathrm{H}_{2} \mathrm{O}=0.95\right)$ leads to a significant broadening of the signals of tetrahedrally coordinated aluminum. Simultaneously, the amount of five- and six-coordinated aluminum increases strongly. At even higher water loading a broadening of the signals of tetrahedrally coordinated aluminum occurs which conceals the original doublet. After complete saturation with water more than $40 \%$ of the originally four-coordinated aluminum is transformed into fiveand six-coordinated aluminum.

To help distinguish between the different possibilities for broadening of the spectral features observed in the DOR experiments, MAS spectra were also recorded. Slow MAS $(1.0$ $\mathrm{kHz}$ ) yielded broad spectra which narrowed considerably upon applying high-power proton decoupling (Figure 7, traces 1 and 2 ), indicating that dipolar broadening is apparent at this low spinning frequency. The broad and featureless spectra obtained

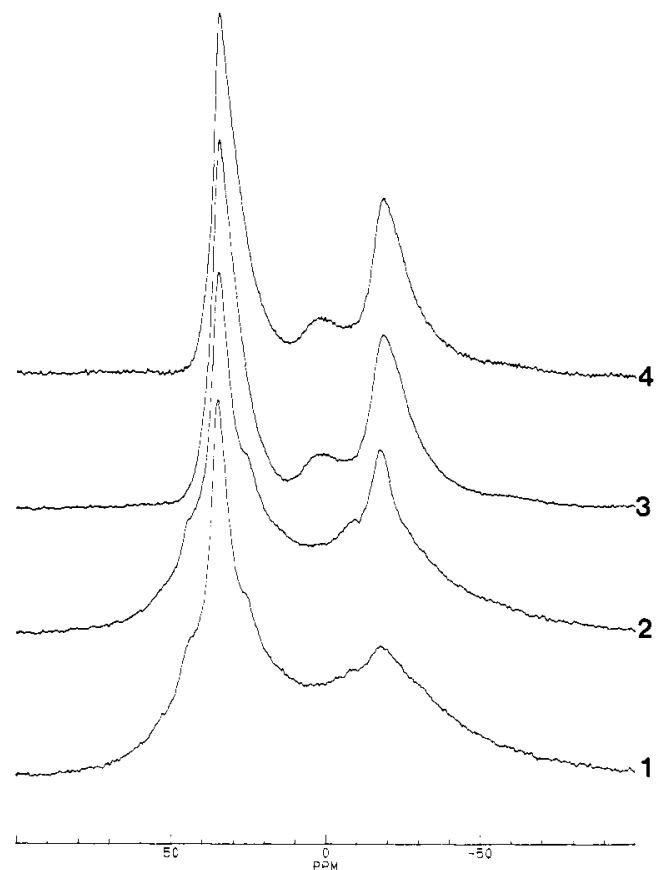

Figure 7. ${ }^{27} \mathrm{Al}$ MAS spectra of fully hydrated AFI-2: $1.0 \mathrm{kHz}$ (trace 1), $1.0 \mathrm{kHz}$ with high-power decoupling (trace 2 ), $10.0 \mathrm{kHz}$ (trace 3 ), and $10.0 \mathrm{kHz}$ with high-power decoupling (trace 4).

in these slow MAS experiments confirm the correctness of the DOR measurements. (After a stop of the inner rotor, in fact, MAS spectra would be recorded with a spinning frequency of 850-1000 Hz.) At high MAS frequencies spectra are obtained which are only slightly broader than the DOR spectra, independent of the application of high-power dipolar decoupling (Figure 7, traces 3 and 4). This is expected since MAS frequencies larger than the heteronuclear dipolar coupling constant will remove this interaction from the spectrum. From these results, together with the DOR experiments, it can be concluded that broadening of the spectral features is largely due to a dispersion in chemical shifts after hydration. A minor influence of the quadrupolar effect of ${ }^{27} \mathrm{Al}$ environments can be deduced from the differences in line widths of MAS and DOR spectra. Nonselective hydration would produce a large distribution of ${ }^{27} \mathrm{Al}$ environments, leading to a spread of the resonances over a large spectral range.

The formation of five-coordinated aluminum upon water adsorption was not observed for AEL samples. ${ }^{2}$ There, even at very low water loading octahedrally coordinated aluminum was formed. Up to $20 \%$ of the aluminum becomes octahedrally coordinated, and maximally four lines are observed in the region where the resonances of tetrahedrally coordinated aluminum occur (Figure 8). Combination of the quadrupolar coupling constants and the local symmetries derived from X-ray diffraction data enabled us to show that the $\mathrm{Al}_{2}$ site of AEL becomes preferentially hydrated ${ }^{2}$ and to denote the observed ${ }^{27}$ AI DOR NMR resonances to the five different crystallographic sites. This assignment will be used here. The conclusion that the $\mathrm{Al}_{2}$ site becomes preferentially hydrated can be reconciled with recent CP-DOR NMR measurements performed on fully hydrated AEL. ${ }^{13}$ In the CP-DOR experiment the octahedral signal is enhanced with respect to the signal of tetrahedrally coordinated aluminum. However, the signals of the tetrahedrally coordinated $\mathrm{Al}_{3}(40.9$ $\mathrm{ppm}),(37.7 \mathrm{ppm})$, and $\mathrm{Al}_{4}(33.6 \mathrm{ppm})$ sites are also visible, while the signal of $\mathrm{Al}_{5}(23.4 \mathrm{ppm})$ is absent in the CP-DOR spectrum. The observed spectrum can be explained if the water molecules (in a cross section view of the AEL channel) are placed close to the $\mathrm{Al}_{2}$ sites and two water molecules near the center of the pore (Figure 9). The water coordinating to an aluminum atom $\left(\mathrm{Al}_{2}\right)$ is 'bounded' to this position, while the water molecules in the center, of the pore are physisorbed and mobile.,414 It is clear that the signals previously assigned by us to the $\mathrm{Al}_{1}$ and $\mathrm{Al}_{3}$ sites 


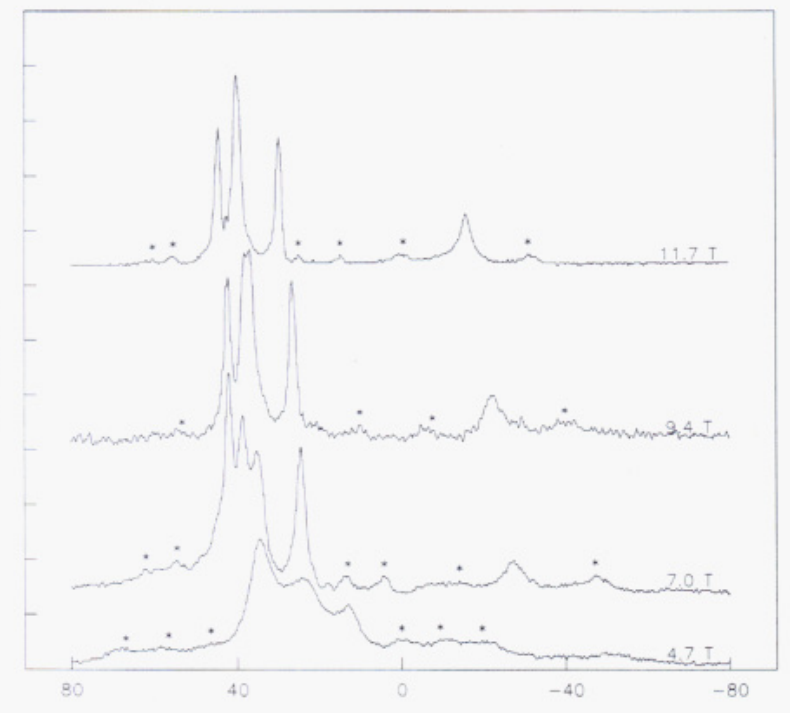

Figure 8. ${ }^{27} \mathrm{Al}$ DOR NMR spectra of fully hydrated AEL measured at different magnetic field strengths: $B_{0}=4.7 \mathrm{~T}$ (trace 1), 7.0 (trace 2), 9.4 T (trace 3), and 11.7 (trace 4).

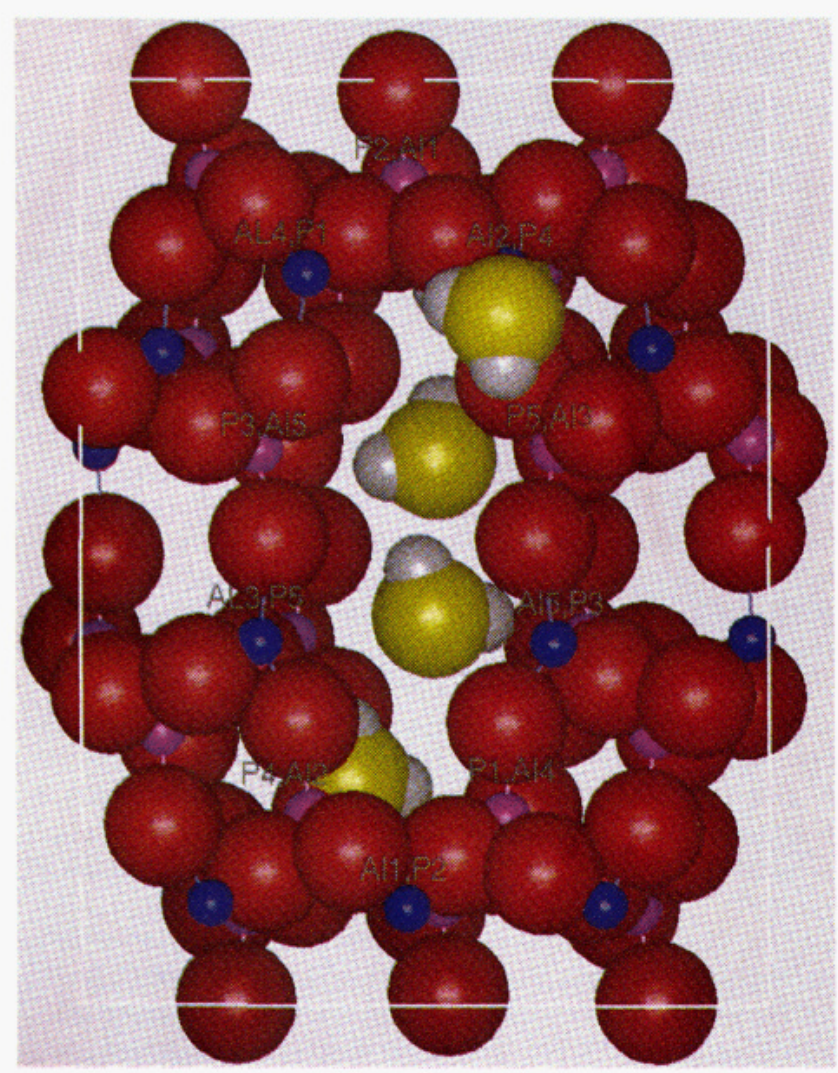

Figure 9. Cross section view of the AEL channel after complete saturation with water.

(neighbors of the $\mathrm{Al}_{2}$ site) are visible, together with the signal of the $\mathrm{Al}_{4}$ site. The distance between the $\mathrm{Al}_{4}$ site and the water molecules bounded to the $\mathrm{Al}_{2}$ site is only slightly larger than the distance between the $\mathrm{Al}_{1}$ and $\mathrm{Al}_{3}$ site and these water molecules (approximately 3.7 and $3.4 \AA$, respectively). The distance between the $\mathrm{Al}_{5}$ site and the rigid water molecules is too large $(6.5 \AA)$ for efficient cross-polarization, while cross-polarization with the physisorbed water molecules is presumably ineffective due to the mobility of these water molecules, resulting in very weak dipolar interactions. ${ }^{13,14}$

The fact that the line widths (at half-height) of the ${ }^{27} \mathrm{Al}$ DOR NMR resonances for AEL do not change upon hydration but
TABLE II: Typical Line Widths of the ${ }^{27} \mathrm{Al}$ DOR NMR Signals of Tetrahedrally Coordinated Aluminum $(\mathrm{Hz})$ at Half-Height of the AFI and AEL Samples Measured at 9.4 T, in the As-Synthesized, Calcined Dehydrated, and Several Equilibrated States (with Adsorbed Methanol, Ammonia, Water, and Acetonitrile)

\begin{tabular}{|c|c|c|c|c|c|c|}
\hline sample & $\begin{array}{c}\text { as } \\
\text { synth }\end{array}$ & dry & $\mathrm{H}_{2} \mathrm{O}$ & $\mathrm{CH}_{3} \mathrm{OH}$ & $\mathrm{CH}_{3} \mathrm{CN}$ & $\mathrm{NH}_{3}$ \\
\hline $\begin{array}{l}\text { AFI } \\
\text { AEL }\end{array}$ & $\begin{array}{r}1170 \\
960\end{array}$ & $\begin{array}{l}590 \\
390\end{array}$ & & & $\begin{array}{l}650(16.6) \\
430(7.0)\end{array}$ & $\begin{array}{l}1220(18.6) \\
1340(13.3)\end{array}$ \\
\hline
\end{tabular}

${ }^{a}$ Numbers in parentheses are weight percent.

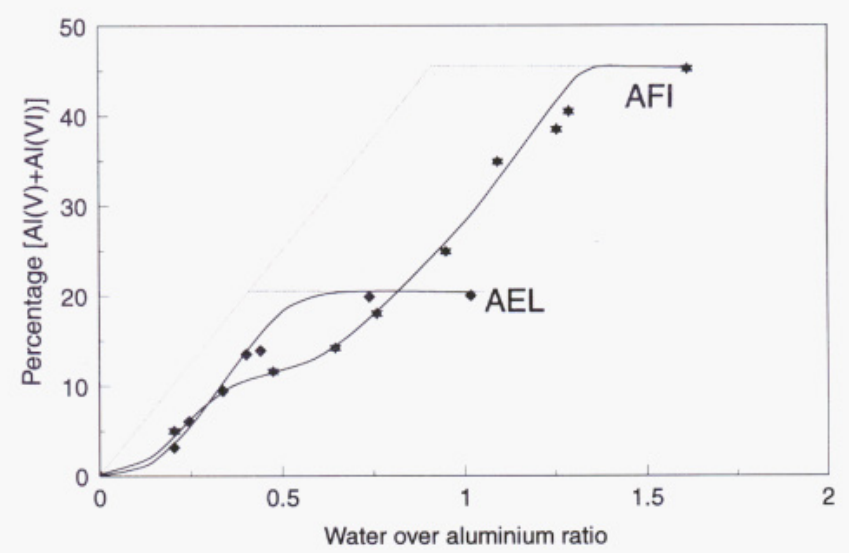

Figure 10. Percentage $(\mathrm{Al}(\mathrm{V})+\mathrm{Al}(\mathrm{VI}))$ as a function of the water content of AFI and AEL.

their relative positions (shifts) do is caused by symmetry changes of the lattice induced by water adsorption. In the dry state (three different T-sites) some of the aluminum resonances are (partially) overlapping, leading to broad envelope of signals. Upon hydration the number of different $\mathrm{T}$-sites is increased to five. The originally overlapping signals are now split into separate resonances.

For AFI hydration seems to occur in a more random fashion. There seem to be three closely related T-sites (see above), so only little preference for hydration of one particular aluminum site can be expected. Furthermore, preferential hydration does not explain the broadening of the ${ }^{27} \mathrm{Al}$ DOR NMR signals (see Table II) of tetrahedrally coordinated aluminum. For two cases where preferential hydration is proven, namely VFI and AEL, the ${ }^{27} \mathrm{Al}$ NMR signals of tetrahedral coordinated aluminum are relatively narrow. Furthermore, partial hydration does not lead to a decrease of one of the three ${ }^{27} \mathrm{Al}$ NMR signals in the tetrahedral region, but rather to a gradual decrease of all signals and finally to broadening (Figure 6). This broadening is probably caused by a variety of different T-sites, leading to a broad envelope of NMR resonances.

The amount of five- and six-coordinated aluminum as a function of the water content of the AEL and AFI samples is plotted in Figure 10. In the AEL type molecular sieve all water adsorbed $\left(\mathrm{H}_{2} \mathrm{O} / \mathrm{Al}<0.55\right)$ is interacting specifically with the $\mathrm{Al}_{2}$ site, leading to octahedrally coordinated aluminum. Only at very low water loading $\left(\mathrm{H}_{2} \mathrm{O} / \mathrm{Al}<0.07\right)$ no five- and/or six-coordinated aluminum could be observed. For the AFI type molecular sieves a somewhat different behavior is observed. At low water laoding the amount of five- and six-coordinated aluminum is less than can be expected for specific interaction of water with an aluminum site (dashed line in Figure 10). Only above an $\mathrm{H}_{2} \mathrm{O} / \mathrm{Al}$ ratio of $0.75(11-12 \mathrm{wt} \%)$ is a strong increase in the amount of five- and six-coordinated aluminum observed, in the same region where a pronounced broadening of the tetrahedrally coordinated aluminum is observed. This is in agreement with the ${ }^{2} \mathrm{H}$ NMR study performed on this system by Goldfarb et al. ${ }^{4}$ There, no octahedrally coordinated aluminum was observed with ${ }^{27} \mathrm{Al}$ MAS NMR at water loadings up to $5 \mathrm{wt} \%$. Moreover, ${ }^{2} \mathrm{H}$ NMR showed the existence of mobile water only. 
Considerable changes are observed in the XRD patterns after water adsorption. For AEL the reflections at low $2 \theta$ angles decrease strongly in intensity, which is ascribed to the interaction of water with a part of the T-atoms. The position of several lines in the diffractogram changes due to the deformation of the pores by water adsorption; the pores become more elliptical after water adsorption. ${ }^{15}$

A decrease of the intensities at low $2 \theta$ angles was also observed for the AFI samples. The observation that water coordinates to part of the aluminum atoms is in line with the above-mentioned explanation. However, no significant change of peak positions is observed after water adsorption, indicating that the symmetry and pore structure of the AFI system do not change after water adsorption.

Methanol Adsorption. The adsorption of methanol in AFI and AEL does not lead to the formation of five- and/or sixcoordinated aluminum. However, significant broadening of the resonances attributed to tetrahedrally coordinated aluminum is observed. For AEL the line width increases from 400 to approximately $650 \mathrm{~Hz}$ for $850 \mathrm{~Hz}$ DOR (outer rotor) measured at 9.4 T; for AFI this increase is even more drastic, 600-1200 $\mathrm{Hz}$. MAS measurements performed at $10.0 \mathrm{kHz}$ with dipolar decoupling yield a line width of $1700 \mathrm{~Hz}$ for the AFI sample and a line width of $770 \mathrm{~Hz}$ for the AEL sample. Clearly, some secondorder quadrupolar broadening is apparent in the MAS spectra, leading to slightly broader lines than in DOR spectra. However, the major cause of the broadening of the spectral features in fast MAS and in DOR spectra upon methanol adsorption stems from chemical shift dispersion, which in turn indicates changes in the framework geometry (i.e., Al-O-P angles) brought about by the adsorbed methanol. The line width of the as-synthesized sample, with the template in the pores, is also broadened in the presence of the template.

XRD measurements performed on these samples indicate that methanol adsorption leads to some small but significant changes in the observed pattern for AEL, while the diffraction pattern of AFI seems unaffected. No decrease in intensities of reflections at low $2 \theta$ angles was observed, suggesting no specific interaction of methanol with the T-atoms in AFI and AEL type molecular sieves, in line with the absence of five- and/or six-coordinated aluminum in the ${ }^{27} \mathrm{Al}$ DOR NMR spectra.

Acetonitrile Adsorption. The absence of five- and/or sixcoordinated aluminum after methanol adsorption can be due to sterical constraints and/or the dipole moment of the molecule. To distinguish between these parameters, acetonitrile and ammonia adsorptions were studied. Acetonitrile is bulkier than methanol but has a much larger dipole moment (3.92 D instead of $1.70 \mathrm{D}$ ), while ammonia is smaller but has a smaller dipole moment (1.3 D). The ${ }^{27} \mathrm{Al}$ DOR NMR spectra after acetonitrile adsorption give no indication of five- or six-coordinated aluminum. It therefore seems that sterical constraints play a major role in controlling the interaction of polar molecules with aluminum in this type of molecular sieve.

Moreover, the adsorption of acetonitrile has only minor influences on the line widths of the ${ }^{27} \mathrm{Al}$ DOR NMR resonances. The intensity of the spinning sidebands is, however, slightly increased (increased chemical shift anisotropy). The XRD patterns before and after acetonitrile adsorption are identical.

Ammonia Adsorption. Ammonia is a small molecule with a small dipole moment (1.3 D). Goldfarb et al. reported ${ }^{27} \mathrm{AI}$ MAS NMR spectra of AFI with adsorbed ammonia. Upon adsorption five-and six-coordinated aluminum was formed. Here, ammonia adsorption on AFI (18.6 wt \%) and AEL (13.3 wt \%) was studied with ${ }^{27} \mathrm{Al}$ DOR NMR and XRD. Ammonia adsorption on the two types of molecular sieves resulted in the formation of fiveand six-coordinated aluminum in both cases. The relative amounts are, however, somewhat different for the two types of molecular sieves (Figure 11). The part of the aluminum which remains

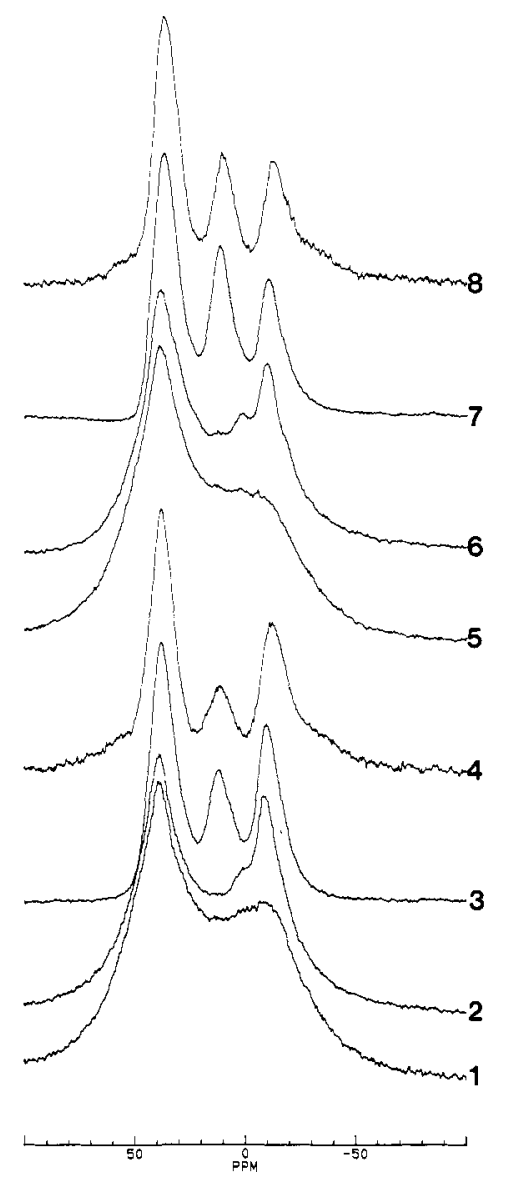

Figure 11. ${ }^{27} \mathrm{Al}$ MAS and DOR NMR spectra of AFI (traces 1-4) and AEL (traces 5-8) molecular sieves with adsorbed ammonia (9.4 T): MAS, $1.0 \mathrm{kHz}$ (traces 1,5 ); MAS, $1.0 \mathrm{kHz}$, high-power decoupling (traces 2 , 6); MAS, 10.0 (traces 3, 7); DOR, $1000 \mathrm{~Hz}$ (traces 4, 8).

four-coordinated appears to be approximately equal for the two structure types (46\% and $52 \%$ for AFI and AEL, respectively). Goldfarb et al. observed two types of ammonia with ${ }^{2} \mathrm{H}$ NMR of deuterated ammonia adsorbed on AFI type molecular sieves. The motion of about $50 \%$ of the ammonia was limited to a threefold jump; this is probably the ammonia bounded to the aluminum site. The motion of the other $50 \%$ (physisorbed ammonia) was not limited. This is in good agreement with the ${ }^{27} \mathrm{Al}$ DOR NMR measurements.

MAS spectra were recorded to find out the reason for the broad resonances observed in the DOR spectra. At low MAS frequencies $(1.0 \mathrm{kHz})$ broad spectra are obtained (Figure 11, traces 1 and 5) which become narrower after applying highpower proton decoupling (Figure 11, traces 2 and 6), indicating the presence of dipolar interactions. MAS spectra recorded at different spinning frequencies indicated that the dipolar interaction is removed from the spectrum at $6-7 \mathrm{kHz}$. The spectra recorded at a MAS frequency of $10.0 \mathrm{kHz}$ (Figure 11 , traces 3 and 7), with or without decoupling, are just slightly broader than the DOR spectra recorded with a spinning frequency of $1000 \mathrm{~Hz}$ (traces 4 and 8). Again, the main reason for broadening of the DOR spectra stems from chemical shift dispersion, although minor influences of quadrupolar interactions play a role in the MAS spectra. MAS spectra recorded with high-power decoupling at different MAS frequencies indicated that the CSA is removed from the spectrum at approximately $3 \mathrm{kHz}$.

In the case of AEL the amount of five-coordinated aluminum $(20 \%)$ is slightly less than the amount of octahedrally coordinated aluminum $(28 \%)$, whereas the amount of five-coordinated aluminum (14\%) is much less than the amount of octahedrally coordinated aluminum ( $40 \%)$ in the case of AFI. The higher amount of five-coordinated aluminum in the AEL type molecular sieves, with respect to the AFI type molecular sieves, might be 


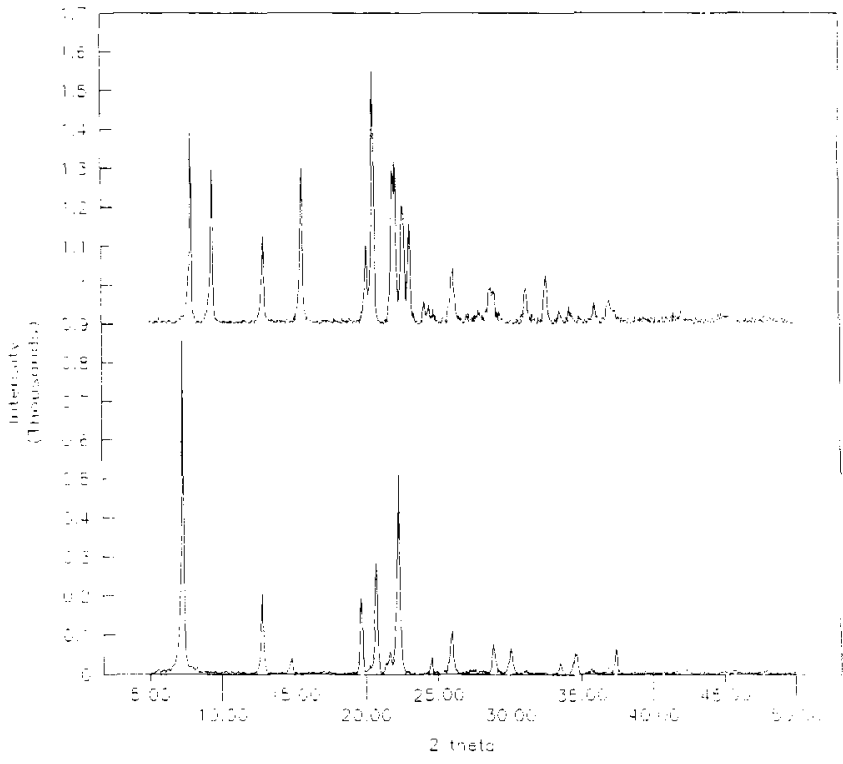

Figure 12. XRD patterns of AFI (bottom) and AEL (top) molecular sieves after adsorption of ammonia.

explained by the small pores of AEL. The space is too limited to get octahedral coordination of all interacting aluminum atoms.

Only minor changes are observed in the XRD patterns of AFI after ammonia adsorption. The intensities of some reflections decrease, but the position of the reflections remains unchanged. For AEL a somewhat different behavior is observed. A slight decrease of intensity is observed, which is recovered after ammonia desorption and a shift of the most intense reflection to lower $2 \theta$ values. This shift is opposite to the shift observed after water adsorption. It is, however, clear that ammonia behaves quite differently than water (Figure 12).

\section{Conclusions}

${ }^{27} \mathrm{Al}$ DOR and ${ }^{31 P}$ MAS NMR performed on AFI samples indicate that three crystallographically different $T$-sites can be distinguished in the structure of dehydrated AFI. Spectral simulations of the DOR and MAS spectra at different magnetic field elucidate that the three different $T$-sites exist in a $1: 1: 1$ ratio. The quadrupolar parameters and isotropic chemical shifts of these sites were determined by spectral simulations of the DOR and MAS spectra.

The interactions of water, methanol, acetonitrile, and ammonia with framework aluminum atoms in AFI and AEL were studied. Water and ammonia are able to transform part of the tetrahedrally coordinated aluminum atoms into five- and/or six-coordinated aluminum. Methanol and acetonitrile are too bulky to coordinate to the aluminum atoms in AFI and AEL type molecular sieves.

Hydration of AEL occurs in a selective way. The aluminum site becomes octahedrally coordinated. This is confirmed by recent CP-DOR experiments performed on the same sample. Partial hydration of AFI showed that broadening of the ${ }^{27} \mathrm{Al} \mathrm{DOR} \mathrm{NMR}$ signal occurs above $\approx 11-12 \mathrm{wt} \%$ water adsorption. Unlike in AEL, this interaction seems to occur in a random fashion.

Acknowledgment. The authors are indebted to Dr. A. Samoson for providing part of the DOR spectra and for many helpful discussions.

\section{References and Notes}

(1) Richardson, J. W., Jr.; Pluth, J. J.; Smith, J. V. Acta Crystallogr. 1987, C43, 1469-1472.

(2) Peeters, M. P. J.; de Haan, J. W.; van de Ven, L. J. M.; van Hooff, J. H. C. J. Phys. Chem. 1993, 97, 5363 .

(3) Jelinek, R.; Chmelka, B. F.; Wu, Y.; Davis, M.E.; Ulan, J.G.;Gronsky, R.; Pines, A. Catal. Lett. 1992, 15, 65-73.

(4) Kustanovich, I.; Goldfarb, D. J. Phys. Chem. 1991, 95, 8818-8823.

(5) Peeters, M. P. J.; van de Ven, L. J. M.; de Haan, J. W.; van Hooff, J. H. C. J. Chem. Soc., Chem. Commun. 1992, 1560-1562. $83-87$.

(6) He, H.; Kolodziejski, W.; Klinowski, J. Chem. Phys. Lett. 1992, 200, 1982.

(8) Wilson, S. T.; Flanigen, E. M. U.S. Patent 4.567.029, 1986.

(9) Samoson, A.; Lippmaa, E. J. Magn. Reson. 1989, 84, 410.

(10) Dong, J.; Li, J.; Liu, G.; Wu, F.; Chang, J.; Xu, W. J. Chem. Soc., Chem. Commun. 1992, 277-278.

(11) Engelhardt, G.; Michel, D. High-Resolution Solid State NMR of Silicates and Zeolites; John Wiley \& Sons: Chichester, 1987; p 61.

(12) Ghose, S.; Tsang, T. Am. Mineral. 1973, 58, 748-755.

(13) Wu, Y.; Lewis, D.; Frye, J. S.; Palmer, A. R.; Wind, R. A. J. Magn. Reson. 1992, 100, 425-430

(14) Goldfarb, D.; Li, H. X.; Davis, M. E. J. Am. Chem. Soc. 1992, 114, $3690-3697$.

(15) Khouzami, R.; Coudurier, G.; Lefebvre, F.; Vedrine, J. C.; Mentzen, B. F. Zeolites 1990, 10, 183-188. 